\title{
Association of objective major life events with the delivery of preterm babies
}

\author{
T C Weerasuriya ${ }^{1}$, J Wijeratne ${ }^{1}$, D Wijegunawardena ${ }^{1}$, S Weerasooriya ${ }^{1}$
}

Sri Lanka Journal of Child Health, 2000; 29: 15-17

(Key words: Life events, preterm babies)

\begin{abstract}
Introduction In many instances of pre-term deliveries a definite cause cannot be identified. Major objective life events may be associated with some of these cases.
\end{abstract}

Objectives To assess the significance of major objective life events in preterm deliveries.

Design Cross-sectional case-control study.

Method A pre-tested questionnaire was filled by the mothers under supervision. 100 cases of preterm deliveries and 100 cases of term deliveries were analysed.

Results A sudden reduction of income, hospitalisation of the mother for non-obstetric causes, hospitalisation of an immediate family member and assault by the husband were significantly associated with preterm deliveries. Death of an immediate family member, instances of husband working in the war-torn areas of north and east and a long term illness of a close relative were events which were not significantly associated with pre-term deliveries. $57 / 100$ pre-term deliveries as compared to $21 / 100$ controls had experienced one or more stressful life events $(\mathrm{P}<0.05)$.

Conclusions One or more stressful life events were associated with pre-term delivery.

\section{Introduction}

Pre-term deliveries are an important cause of neonatal morbidity. However in many instances there are no apparent obstetric or medical causes associated with the delivery of pre-term babies. Our hypothesis is that major objective life events (physical, psychological or social) experienced during pregnancy may be associated with pre-term deliveries.

\footnotetext{
${ }^{1}$ Student, Faculty of Medicine, Colombo
}

\section{Objective}

To investigate for an association between objective major life events experienced during pregnancy and pre-term deliveries.

\section{Design}

A cross sectional case-control design was used. The study population consisted of mothers aged between 20-35 years with a gestational period of $<37$ weeks (calculated according to the mother's dates) with no postnatal complications. Only mothers in their first or second pregnancy were included. Those with known obstetric and gynaecological complications indicated in Table 1 were excluded from the study group.

The control group comprised infants born by vaginal delivery at or beyond 37 weeks (calculated according to the mother's dates) to an uncomplicated mother aged between 20-35 years in her first or second pregnancy who had none of the above exclusion criteria.

The objective major life events are given in Table 2. The study was conducted in December 1997 at De Zoysa Maternity Hospital, Castle Street Hospital for Women, Lady Ridgeway Hospital, Sri Jayawardenapura Hospital and Kalubowila Teaching Hospital.

\section{Table 1}

Obstetric and gynaecological complications

Past history of abortion

Pregnancy induced hypertension

Gestational diabetes

Renal disease

Malaria

Measles

Rubella

Fever lasting more than seven days

Any known gynaecological problem

Pre-existing diabetes

Pre-existing hypertension 
Table 2

\section{Objective major life events}

Husband subjected to terrorist attack

Death of husband due to terrorist attack

Wounding of husband due to terrorist attack

Husband missing after a terrorist attack

Husband is an alcoholic

Husband assaults physically

Husband assaults verbally

Husband abroad during pregnancy

Husband separated during pregnancy

Husband divorced during pregnancy

Hospitalisation of self during pregnancy for conditions other than obstetric causes

Close family member hospitalised during pregnancy

Chronic illness of husband or child

Attempted suicide by husband or child

Arguments with husband or child

Arguments with neighbors

Husband arrested by police

Court conviction of self

Sudden decrease of income by more than two thousand rupees

Inability to pay a debt.

\section{Methodology}

A pre-tested questionnaire was given to the mothers to be filled by themselves. Members of the study group were available for clarifications. A serial count was maintained and when a total of 100 cases and 100 controls were reached the process was stopped.

\section{Results (Table 3)}

A sudden reduction in income by more than Rs. 2000 was experienced by 17 cases and 05 controls. The P value was $<0.05$.

Hospitalisation of the mother for a non-obstetric cause was experienced by 24 cases and by 08 controls with a $\mathrm{P}$ value of $<0.05$.

Hospitalisation of immediate family member during the pregnancy was encountered by 20 cases and 07 controls with a $\mathrm{P}$ value $<0.05$.

Five cases and 03 controls have encountered a death of an immediate family member during the period of pregnancy which had a $\mathrm{P}$ value $>0.05$. (not significant)

Nineteen cases and 01 control had been assaulted by the husband during pregnancy. The $\mathrm{P}$ value here was $<0.05$.

Table 3

Results

\begin{tabular}{|c|c|c|c|c|}
\hline Stressful life events & Cases & Controls & Chi square values & Significance at $P<0.05$ \\
\hline $\begin{array}{l}\text { Sudden reduction of income by more } \\
\text { than } 2000 \text { rupees } 17057.35 \text { positive }\end{array}$ & 17 & 05 & 7.35 & positive \\
\hline $\begin{array}{l}\text { Hospitalisation of self for non } \\
\text { obstetric cause } 24089.52 \text { positive }\end{array}$ & 24 & 08 & 9.52 & positive \\
\hline $\begin{array}{l}\text { Hospitalisation of immediatefamily } \\
\text { member during the pregnancy }\end{array}$ & 20 & 07 & 7.24 & positive \\
\hline $\begin{array}{l}\text { Death of immediate family member } \\
\text { during pregnancy }\end{array}$ & 05 & 03 & 0.03 & not significant \\
\hline Physical assault by husband & 19 & 01 & 10.06 & positive \\
\hline Husband in North and East & 06 & 01 & 2.37 & not significant \\
\hline Chronic illness of husband or child & 00 & 01 & 00 & not significant \\
\hline Total & 57 & 21 & & significant \\
\hline
\end{tabular}


Six cases had their husbands working in the North and East while only 01 control had her husband working in the war zone. The $\mathrm{P}$ value was $>0.05$ (not significant).

A long term illness of a close relative was experienced by only 01 control with a $\mathrm{P}$ value of $>0.05$ (Yates corrective applied).

Stressful life events with zero respondents are not mentioned. 57 of the mothers among them had experienced one or more stressful life events during the period of pregnancy while 21 of the mothers in the control group had encountered a stressful event during the period of pregnancy. This was significant statistically at $\mathrm{P}$ value $<0.05$ (Table 4 ).

Three of the cases had experienced a stressful life event at a POA of 01 month while 09 controls had the same experience. One mother out of the controls experienced a stressful life event at a POA of 02 months. Four mothers of the control group had encountered a stressful life event at 03 months of gestation. Out of the cases 28 , 23, 02 had experienced a stressful life event at a POA of respectively $04,05,06$ months, while 01 case and 07 controls had undergone similar experience r'qht throughout the period of pregnancy (Table 5).

Table 4

Stressful life events during pregnancy

\begin{tabular}{|l|c|c|}
\hline $\begin{array}{c}\text { No of stressful } \\
\text { life events }\end{array}$ & $\begin{array}{c}\text { Number of } \\
\text { cases }\end{array}$ & $\begin{array}{c}\text { Number of } \\
\text { controls }\end{array}$ \\
\hline None & 43 & 79 \\
\hline One or more & 57 & 21 \\
\hline Total & 100 & 100 \\
\hline
\end{tabular}

Table 5

Stressful events during different months of pregnancy

\begin{tabular}{|c|c|c|}
\hline Months & No. of cases & No. of controls \\
\hline 1 & 03 & 09 \\
\hline 2 & 00 & 01 \\
\hline 3 & 00 & 04 \\
\hline 4 & 28 & 00 \\
\hline 5 & 23 & 00 \\
\hline 6 & 02 & 00 \\
\hline 7 & 00 & 00 \\
\hline 8 & 00 & 00 \\
\hline 9 & 00 & 00 \\
\hline 10 & 00 & 00 \\
\hline $\begin{array}{l}\text { Right } \\
\text { throughout } \\
\text { pregnancy }\end{array}$ & 01 & 07 \\
\hline Total & 57 & 21 \\
\hline
\end{tabular}

\section{Discussion}

As our objective was to study the association of objective major life events and the delivery of preterm babies we defined an objective major life event as an instance which has a psychological impact on a person's life, which is referred to as stress. These events, when experienced need a lot of readjustments in one's life. In identifying the life events, a scale originally standardised on a population of pregnant women, known as a modified life events inventory was used ${ }^{1}$. It is evident from the above results that reduction in income ( $P<0.05)$, hospitalisation of self $(P<0.05)$, hospitalisation of an immediate family member $(\mathrm{P}<0.05)$, and physical assault by husband $(\mathrm{P}<0.05)$ are the major objective life events that has a statistically significant association with preterm delivery. Among the cases $53 \%$ had experienced one or more stressful life events during the second trimester, while $14 \%$ controls had encountered a similar event during the first trimester. $07 \%$ controls had experienced stressful life event during the entire duration of the pregnancy.

A similar study on the association of major objective life events with low birth weight had been done in the UK in 1991 and they had found a statistically significant association between the two ${ }^{2}$.

The major drawback of our study was recall bias. Mothers who have delivered a preterm baby are more likely to associate that event with some objective major life event than mothers who have delivered at term. This may have led to the high level of significance seen in our study.

\section{Conclusion}

One or more objective major life events are statistically associated with pre-term delivery. Out of them reduction in family and income, hospitalisation of immediate family member and assault by husband were found to significantly influence a pre-term delivery.

\section{Acknowledgements}

We thank H P P Warnakulasuriya, W A $\mathrm{T}$ I Weerasingha, W S Widhanapathirana, Dr Prasanna Cooray, Professor Dulitha Fernando, Dr Manouri Senanayake, Dr Indumal Dias, Directors of D. M. H., L. R. H., Castle Street Hospital for Women, Kalubowila Hospital and Sri Jayawardenapura Hospital for their invaluable help.

\section{References}

1. Hunt R W, Linda P. Modified life events inventory. British MedicaI Journal 1984; 288:1191-4.

2. Mutale T, Creed F, Maresh M, Hunt L. Life events and low birth weight - analysis by infants preterm and small for gestational age. British Journal of Obstetrics and Gynaecology 1 991; 98:166-72. 